Sto 05

DIAGNOSIS AND THERAPY OF MALIGNANT GASTRIC LYMPHOMA

K. Albrecht, M. Kroll, F.W. Eigler, K. Höffken The rare gastric lymphoma is of surgical interest, since its behaviour is different from that of gastric carcinoma. The advent of newer treatment regiments suggests that patient survival can be improved greatly. We therefore retrospectively analysed the cards of 376 patients operated on a gastric malignoma from 1/1972 - 9/1985. We found 18 patients $(4,8$ o) with non-Hodgkin's Lymphoma, 12 with primary lymphoma, 6 with disseminated lymphoma with gastric involvement. The histological classification yielded $16 \mathrm{high}$ grade lymphoma cases. In 6 cases the correct diagnosis was pre- or intraoperatively unknown. Indication for surgery were local tumor symptoms. In all 6 cases of disseminated lymphoma surgery was necessary to cope with severe local complications (bleeding, perforation) due to systemic treatment (chemotherapy, irradiation).

The perioperative letality was 2 from 12 primary lymphomas, due to extended resection under the assumption of carcinoma. From 6 patients with disseminated lymphoma 3 died related to surgery. Postoperative systemic therapy/irradiation was applied to 10 out of 13 surviving patients. Later letality due to tumor progress was 1 (primary) vs. 3 (disseminated 1 ymphoma). 9 patients (primary lymphoma) are still alive (1/2-11 yrs.). We conclude: Good prognosis of operated primary lymphoma combined with postoperative systemic therapy (even if non curatively resected) require 1) correct diagnosis if necessary intraoperatively (frozen section) for sufficient staging, 2) limited resection, 3) resection prior to systemic therapy (in advanced stages).

Abt.f.Allg.Chir.des Universitätsklinikum Essen, HufelandstraBe 55, 4300 Essen 1

\section{Sto 06}

THE HETEROGENEITY OF EARLY GASTRIC CANCERS WITH THE EXCEPTION OF MINUTE EARLY GASTRIC CANCERS F.Borchard and S. Keller

The heterogeneity of tumours can be expected to be minimal in early clonal evolution and to progress with advanced tumour growth because of genetic instability. This problem was investigated in 115 early gastric cancers (egc)including 14 minute egc of $5 \mathrm{~mm}$ in diameter or less. Ali tumours were completely blocked and processed conventionally.- According to Laurén's classification the intestinal and diffuse carcinomas were judged either as pure types or mixed types with intestinal and diffuse parts the ratios of which are given in the following table:

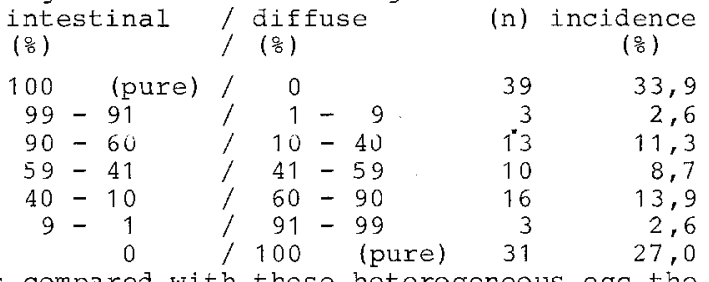

As compared with these heterogeneous egc the included 14 minute egc showed only minimal heterogeneity: only 1 of these displayed both intestinal and diffuse elements while there were 7 purely intestinal and 6 purely diffuse types.

These results support the view that egc may start as clonal growth which either by stepwise mutation or by confluence of heterogeneously differentiated egc progresses to advanced egc with heterogeneous morphology.

Pathologisches Institut der Universität, Moorenstrabe 5, 4000 Düsseldorf , FRG
Sto 07

IYMPH NODE STAGING IN EARTY GASTRIC (AANCER. M. Bues and Th. Griter In connection with the German Validity Study on Gastric Carcinoma, the pattern of lymphogenous metastazation is studied in early gastric carcinoma (egc). The material is an unselected collective of 161 egc patients, among a total of 1444 gastric eancer patients entered in the study. All specimen were closely investigated and classified according to IAURtiv. Iymph node metastases were found in $13,7 \%$ of all egc. The pathologist's nodal staging reveals a distinct correlation with the histologic type of the primary: the diffuse type of egc tends to metastasize twice as often (20\%) as the intestinal type; the trend is significantly reflected in the involvement of $\mathbb{N 2}$ and $N 1$ stetions. N3 nodes are hardly, if ever, involved. There is only a minor correlation with the primary's depth of invasation: in the submucosal type of egc, metastatic frequency is $14 \%$ as opposed to $12 \%$ in the mucosal type; the increased involvement concerns mainly the $\mathbb{N 2}$ station. Correlation with multi-

focality is not recognizable; the multifocal egc (nearly 11\%) seems to metastasize in the same mode and quantity as do unifocal tumors.

Conclusions:

Staging by criteria of nodal involvement reveals strong correlation of egc with the IAUREN type, less so with the depth of invasion, and next to none with the multifocality of primaries. Since Iymphe node involvement in egc concerns almost exclusively the stations $\mathrm{N} 1$ and $\mathbb{N} 2$, only surgical dissection including the nodes along the

AA.gastricae sinistra et dextra, the A.lienalis, the Truncus coeliacus, and the A.hepatica comm. will ensure truly curative gastric resection.

Chirurgische Universitatsklinik und Poliklinik, Jungeblodtplatz $1, D-4400$ Minster.

Sto 08

PROGNOSTIC FACTORS OF GASTRIC CARCINOMA RECURRANCE

E.H.J.Keller, E.Düll

From 1974 till 19841010 patients with adenocarcinoma of the stomach were treated. 46 of them had a recurrence. This is equivalent to $4.5 \%$ of all resp. $12,2 \%$ of all operated patients $(n=375) .69 \%$ of all operated patients were in the follow-up program. The median time between the operation of the primary and the diagnosis of the relapse was 12,5 months.

A good prognosis relating to the disease free interval had female sex, localisation of the primary in the lower third, after distal resection, stage III or IV resp. early cancer, the dedifferenciated carcinoma resp. the intestinal type of Laurdn.

The prognosis was good following diagnosis of relapse in case of male sex. Karnofsky 70-100\%, CEA less than $3 \mathrm{ng} / \mathrm{ml}(\mathrm{n} \leqslant 2,5 \mathrm{ng} / \mathrm{ml})$, surgical or cytostatic therapy. After therapy of recurrence the following factors were important to survival female sex, age below 50 years, local recurrence without lymphogenic or hematogenic metastases, stage IV or localisation in the distal third and the poorly differentiated carcinoma or intestinal type of Lauren.

Distal tumors allowing a distal resection had a better prognosis than proximal tumors, though these were resected more often potentially curatively treated by gastrectomy than distal tumors (90\% resp. $70 \%)$.

Chirurgische Universitätsklinik

LangenbeckstraBe 1, D-6500 Mainz 1 